\title{
Os contextos investigativos de pensamento criativo em publicações acadêmicas
}

\author{
Investigative contexts of creative thinking in academic publications
}

\author{
Naiara Briega Bortoloci (naibriegabortolocii@gmail.com) \\ Mestranda do Programa de Pós-Graduação em Ensino de Ciências e Educação Matemática na \\ Universidade Estadual de Londrina - UEL \\ Juliana Marciotto Jacob (julianajacobqui@ hotmail.com) \\ Doutoranda do Programa de Pós-Graduação em Ensino de Ciências e Educação Matemática na \\ Universidade Estadual de Londrina - UEL
}

Fabiele Cristiane Dias Broietti (fabieledias@uel.br)

Docente do Departamento de Química e docente e orientadora no Programa de Pós-Graduação em Ensino de Ciências e Educação Matemática na Universidade Estadual de Londrina - UEL

Resumo: O Pensamento Criativo (PC) é almejado em várias áreas do conhecimento e mencionado como uma das 10 competências necessárias para o cidadão contemporâneo. Nesse cenário, a partir de um levantamento em produções acadêmicas, buscou-se responder às seguintes questões norteadoras: Quais as características das produções a respeito do Pensamento Criativo? Em quais contextos investigativos o Pensamento Criativo foi empregado pelos autores das produções? O corpus é composto de 36 publicações que foram analisadas a partir dos pressupostos da Análise de Conteúdo. Em um primeiro movimento foram constatadas algumas características como a temporalidade das publicações, as áreas de conhecimento, bem como os referenciais teóricos utilizados. Em um segundo momento os artigos foram agrupados em categorias (C1-C6) que expressam os diferentes contextos investigativos relativos a: avaliação de PC a partir de distintos instrumentos; sugestão de propostas de ensino que promovam o PC; estudos que relacionam o PC a outros quadros teóricos; ideias e compreensões de professores e alunos acerca do PC; desafios relativos ao PC nas Ciências e artigos que utilizam a expressão PC, sem aprofundá-la. Tais resultados mostram a importância do pensar criativamente na sociedade atual, visto que essa competência tende a influenciar, significativamente, no desenvolvimento profissional, social e pessoal dos cidadãos.

Palavras-chave: Pensamento Criativo; Produções; Criatividade.

Abstract: Creative Thinking (CP) is aimed at in various areas of knowledge and mentioned as one of the 10 competencies needed by the contemporary citizen. In this scenario, from a survey of academic productions, we sought to answer the following guiding questions: What are the characteristics of the productions regarding Creative Thinking? In what investigative contexts was Creative Thinking employed by the authors of the productions? The corpus consists of 36 publications that were analyzed based on the assumptions of Content Analysis. In a first movement, some characteristics were found, such as the temporality of publications, the areas of knowledge, as well as the theoretical references used. In a second step, the articles were grouped into categories (C1-C6) that express the different investigative contexts related to: $\mathrm{CP}$ evaluation from different instruments; suggestion of teaching proposals that promote the

Recebido em: $15 / 07 / 2020$

Aceito em: $1 \% 12 / 2020$ 
$\mathrm{CP}$; studies that link the PC to other theoretical frameworks; ideas and understandings of teachers and students about the $\mathrm{CP}$; challenges related to PC in Sciences and articles that use the expression PC, without going into it further. Such results show the importance of thinking creatively in today's society, as this competence tends to significantly influence the professional, social and personal development of citizens.

Keywords: Creative Thinking; Productions, Creativity.

Resumen: El pensamiento creativo (CP) está dirigido a diversas áreas del conocimiento y se menciona como una de las 10 competencias que necesita el ciudadano contemporáneo. En este escenario, a partir de una encuesta de producciones académicas, buscamos responder las siguientes preguntas orientadoras: ¿Cuáles son las características de las producciones con respecto al pensamiento creativo? ¿En qué contextos de investigación los autores de las producciones emplearon el pensamiento creativo? El corpus consta de 36 publicaciones que fueron analizadas en base a los supuestos del Análisis de Contenido. En un primer movimiento, se encontraron algunas características, como la temporalidad de las publicaciones, las áreas de conocimiento, así como las referencias teóricas utilizadas. En un segundo paso, los artículos se agruparon en categorías (C1-C6) que expresan los diferentes contextos de investigación relacionados con: evaluación de $\mathrm{CP}$ de diferentes instrumentos; sugerencia de propuestas docentes que promuevan el PC; estudios que vinculan la PC a otros marcos teóricos; ideas y entendimientos de maestros y estudiantes sobre el CP; desafíos relacionados con la PC en Ciencias y artículos que usan la expresión PC, sin profundizar en ella. Tales resultados muestran la importancia de pensar creativamente en la sociedad actual, ya que esta competencia tiende a influir significativamente en el desarrollo profesional, social y personal de los ciudadanos.

Palabras-clave: Pensamiento creativo; Producciones; Creatividad.

\section{S TINTRODUÇÃO}

Os termos "processo criativo", "criatividade" e "pensamento criativo" são muitas vezes utilizados no senso comum, sem que se recorram a definições mais precisas. Contudo, alguns estudiosos de diferentes áreas (TORRANCE, 1976; PICHÓNRIVIÈRE, 1999; ALENCAR; BRUNO-FARIA; FLEITH, 2010, OSTROWER, 2013) têm pesquisado tal temática tentando desvendar o emaranhado de significados que envolvem o assunto, a fim de compreender o que são e como se desenvolvem o pensamento criativo e a criatividade, buscando ainda a elaboração de um conceito que possa dar conta não só da pluralidade, mas também da especificidade dos termos em cada domínio proposto.

Na década de 1950, a investigação a respeito de tópicos sobre a criatividade cientificamente fundamentada teve início nos Estados Unidos, sendo esta impulsionada por eventos políticos e tecnológicos. Em 1957, durante a Guerra Fria, os russos 
lançaram no espaço o Sputnik (primeiro satélite artificial) e, dessa forma, os americanos se viram ameaçados em sua supremacia tecnológica, dando início a um gigantesco programa de armamento tecnológico, atrelado ao grande investimento na investigação da criatividade, pois pretendiam "estar na posse de um teste psicológico de criatividade que permitisse o reconhecimento e incentivo de indivíduos criativos" (TSCHIMMEL, 2010, p. 77).

Segundo Ostrower (2013), os comportamentos criativos dos humanos ocorrem na intersecção existente entre a ação consciente, a percepção sensível e as possibilidades do contexto cultural do indivíduo, sendo assim, aprender a pensar se torna uma necessidade e, dessa forma, o pensamento criativo pode ser considerado um fator importante para o progresso de um país por meio do enfrentamento dos desafios presentes na dinâmica de uma sociedade que vive em constante mudança (OSTROWER, 2013).

Partindo do conceito de pensamento divergente ${ }^{1}$ que Guilford desenvolveu 4 parâmetros de avaliação do pensamento criativo, sendo eles: fluidez, flexibilidade, originalidade e elaboração de ideias, parâmetros esses universalmente conhecidos (CHAVERRA-FERNÁNDEZ; GIL-RESTREPO, 2017).

Descrevendo as principais características destes parâmetros, tem-se a fluidez mental de um indivíduo como a sua capacidade de expressar ideias sobre uma determinada circunstância, num dado período de tempo, e flexibilidade mental, quando essa capacidade de expressão está atrelada a uma produção de qualidade (CHAVERRAFERNÁNDEZ; GIL-RESTREPO, 2017).

No que concerne à originalidade, as ideias são assim consideradas quando são únicas e inabituais. O grau de distanciamento em relação às demais soluções já existentes e o quanto esta ideia se afasta do seu conceito inicial, acabam tornando-a mais original (TSCHIMMEL, 2010).

\footnotetext{
${ }^{1}$ Pensamento convergente e pensamento divergente foram dois tipos de pensamento identificados por Guilford (1950) ao tentar desenvolver testes de medida do pensamento criativo, na década de 1950. "Enquanto o pensamento convergente acontece quando são aplicadas determinadas regras e normas aprendidas, o pensamento divergente é um pensamento flexível e ajustado a diferentes objetivos" (TSCHIMMEL, 2010, p. 84).
} 
Segundo Morais e Fleith (2017), a fim de tentar avaliar e quantificar a criatividade que um indivíduo possui, foram elaborados alguns instrumentos:

Testes de pensamento divergente, inventários de atitudes e de interesses, testes de personalidade criativa, inventários biográficos, avaliações por outros e autoavaliações de criatividade, escalas de clima criativo, avaliação de produtos criativos, estudos de indivíduos eminentes (MORAIS; FLEITH, 2017, p. 14).

Avaliar a criatividade, tendo em vista as características individuais, "é então um contexto delicado, no que contém de multiplicidade e de fragilidade, o que é absolutamente esperável dada as características do que é ser criativo" (MORAIS; FLEITH, 2017, p. 18).

Sabemos que o pensamento criativo é uma habilidade desejada em diferentes áreas do conhecimento e entre elas destaca-se o contexto educacional, em que a criatividade pode possibilitar ao estudante uma motivação no processo de aprendizagem, tornando-o mais ativo no ambiente escolar (SILVA, 2017).

Gallon e colaboradores (2019) relatam que projetos escolares, como os clubes de ciências, por exemplo, estimulam a criatividade, e buscam "aprimorar a curiosidade do estudante e transformá-la em um conhecimento válido" (p. 184).

$\mathrm{Na}$ Educação Científica ${ }^{2}$ também se preza pela criatividade, uma vez que os pensamentos criativo e crítico ${ }^{3}$ dos alunos podem ser desenvolvidos durante a vivência de uma pesquisa investigativa, sendo esta capaz de aprimorar as capacidades de observação, reflexão, julgamento, ação e criação. Dessa forma, quando um professor ensina Ciências, o senso de incerteza de seus alunos deve ser despertado, instigando seu espírito investigativo e a sua curiosidade, fazendo com que eles explorem o que ainda é desconhecido (SILVA, 2017).

$\mathrm{Na}$ perspectiva Histórico-Cultural, a qual apresenta Vigotski como teórico fundador, a criatividade é abordada remetendo-a à imaginação, ou seja, à capacidade

\footnotetext{
${ }^{2}$ Justificamos nosso interesse em correlacionar o Pensamento Criativo à área da Educação Científica, uma vez que essa é a área de interesse das autoras.

${ }^{3}$ Neste artigo limitar-nos-emos às discussões sobre o pensamento criativo, contudo, em vários estudos estes dois tipos de pensamentos aparecem articulados. O Pensamento Crítico é defendido (Ennis, 1985, p. 46), como um "pensamento racional, reflexivo, focado naquilo em que se deve acreditar ou fazer". Tenreiro-Vieira (2000, p.20) acrescenta que "esta via racional, permite-lhe analisar, decidir aquilo que é verdadeiro, dominar e controlar o seu próprio conhecimento e adquirir novo conhecimento".
}

Recebido em: 15/07/2020

Aceito em: $1 \% / 12 / 2020$ 
criadora do homem, a qual "antecipa mentalmente a ação, o modo de realizá-la e o resultado esperado dela" (PINO, 2006, p.54).

No que diz respeito à promoção do pensamento criativo na Educação Científica, o Centro de Pesquisa e Inovação em Educação da OCDE realizou uma pesquisa-ação em 11 países, dentre eles o Brasil, com o objetivo de desenvolver "uma linguagem e um entendimento comum sobre o que significa a promoção das competências de criatividade e pensamento crítico no Ensino Fundamental e no Ensino Médio" (VINCENT-LANCRIN, et al., 2020, p. 18).

Tal pesquisa contou com a elaboração de rubricas conceituais para ajudar os professores a compreenderem melhor o significado das competências de criatividade e pensamento crítico, no contexto escolar. Estas rubricas puderam orientar a elaboração de novos planos de aula pelos professores, para diferentes disciplinas escolares (como Ciências, por exemplo), permitindo-lhes uma intencionalidade no desenvolvimento das competências.

Dessa forma, uma atividade pedagógica que esteja alinhada à rubrica da OCDE deve:

1. Despertar nos alunos a necessidade/o interesse de aprender e ter ideias, bem como integrar outras perspectivas disciplinares.

2. Ser desafiadora.

3. Desenvolver claro conhecimento técnico em um ou mais domínios.

4. Incluir o desenvolvimento de um produto.

5. Levar os alunos a desenvolver conjuntamente parte do produto.

6. Abranger problemas que podem ser vistos de diferentes perspectivas.

7. Deixar espaço para o inesperado.

8. Incluir espaço e tempo para os alunos refletirem e darem/receberem feedback (VINCENT-LANCRIN, et al., 2020, p. 31)

Deste modo, o projeto de pesquisa demonstrou que tais competências podem ser ensinadas, aprendidas e avaliadas em escolas tanto do Ensino Fundamental como do Ensino Médio (VINCENT-LANCRIN, et al., 2020).

Diante de tais apontamentos e com o intuito de apresentar um panorama acerca de estudos que investigam o pensar criativamente, estabelecemos como objetivo deste estudo identificar e categorizar produções que discutem o Pensamento Criativo, buscando responder às seguintes questões: Quais as características das produções a respeito do Pensamento Criativo? Em quais contextos investigativos o Pensamento Criativo foi empregado pelos autores? 


\section{ENCAMINHAMENTO METODOLÓGICO}

Neste estudo, o referencial metodológico adotado foi a revisão bibliográfica sistemática. De acordo com Fink (2005), esse método é caracterizado como "sistemático, explícito, abrangente e reprodutível para identificar, avaliar e sintetizar o corpo existente de trabalhos concluídos e produzidos por pesquisadores, acadêmicos e profissionais" (FINK, 2005, p. 03, tradução nossa).

De forma complementar, para sistematizar a revisão bibliográfica proposta, seguimos as etapas descritas por Okoli (2015) que visam a uma revisão organizada, além de discutirem os conteúdos encontrados na literatura, de forma sucinta.

Segundo Okoli (2015), a "primeira etapa de qualquer revisão, exige que os revisores identifiquem claramente o objetivo e as metas pretendidas, essas necessárias para que a revisão seja compreensível para seus leitores" (OKOLI, 2015, p.884, tradução nossa). Atendendo à etapa 1, estabeleceram-se o objetivo e as questões de investigação, descritos anteriormente.

A segunda etapa consistiu em elaborar um protocolo e instruir a equipe envolvida na revisão, isto é, os revisores precisam ser claros e concordar com os procedimentos a serem seguidos durante a revisão. Nessa etapa ocorreu a elaboração de um protocolo com o intuito de detalhar as etapas a serem realizadas no estudo.

A terceira etapa requer que os revisores sejam claros acerca dos estudos que eles consideram relevantes para a revisão, e quais eles desejam eliminar. Okoli (2015) também afirma que "para os estudos excluídos, os revisores devem declarar suas razões práticas para não os considerar, e justificar como a revisão tende a continuar abrangente, dados os critérios de exclusão" (OKOLI, 2015, p.884, tradução nossa).

$\mathrm{Na}$ quarta etapa, os revisores precisam ser explícitos ao descrever os detalhes da busca por literatura. De modo a cumprir a terceira e a quarta etapa desse estudo, os artigos foram selecionados a partir de duas bases de dados: o portal de periódicos da CAPES $^{4}$ e o Scielo 5 . Em ambas as bases utilizou-se a expressão "Pensamento Criativo"

\footnotetext{
${ }^{4}$ O Portal de periódicos da CAPES (Coordenação de Aperfeiçoamento de Pessoal de Nível Superior) é uma biblioteca virtual que reúne e disponibiliza às instituições de ensino e pesquisa, do Brasil, produções científicas nacionais e internacionais. 〈https://www.periodicos.capes.gov.br/>
}

Recebido em: $15 / 07 / 2020$

Aceito em: $1 \% 12 / 2020$ 
nos campos de busca, porém, devido às diferentes opções de filtros entre as duas bases de dados, no portal da CAPES os artigos foram filtrados por "assunto" e, no Scielo, por "resumos". Obteve-se, desta primeira seleção, um total de 42 artigos. Ao serem previamente analisados, foram excluídos os que se encontravam em duplicidade, de modo a resultar em 36 artigos que constituíram o corpus da pesquisa. A busca foi realizada entre os meses de abril a maio de 2020, e não houve recorte temporal.

No Quadro 1 constam os títulos, os periódicos e o ano de publicação dos artigos identificados e analisados. Os artigos codificados como S01 a S30 foram selecionados a partir da base do Scielo; já os artigos codificados de C01 a C06 foram selecionados a partir do portal da CAPES.

Quadro 1 - Artigos selecionados para o corpus da pesquisa.

\begin{tabular}{|c|c|c|}
\hline $\begin{array}{l}\text { Artigos } \\
\text { Scielo } \\
\text { (código) }\end{array}$ & Título do Artigo & Periódico e ano \\
\hline S01 & $\begin{array}{l}\text { The role of creativity in graduate education } \\
\text { according to students and professor }\end{array}$ & $\begin{array}{l}\text { Estudos de Psicologia Vol.36. } \\
2019 .\end{array}$ \\
\hline S02 & $\begin{array}{l}\text { Collective portfolio: assessment of teaching } \\
\text { and learning in health undergraduate courses }\end{array}$ & $\begin{array}{l}\text { Ciência e saúde coletiva. Vol.23. } \\
2018 .\end{array}$ \\
\hline S03 & Overcoming obstacles to creativity in Science & $\begin{array}{l}\text { Estudo de psicologia. Vol.35, n⿳3. } \\
2018\end{array}$ \\
\hline S04 & $\begin{array}{l}\text { Prácticas corporales e innovación en educación } \\
\text { infantil ( } 0-6 \text { a nos): análisis crítico desde la } \\
\text { mirada de expertos }\end{array}$ & $\begin{array}{l}\text { Revista Brasileira de Ciência do } \\
\text { Esporte. Vol.40, nº.3. } 2018\end{array}$ \\
\hline S05 & Traduzir a poesia sonora cientia & $\begin{array}{l}\text { Caderno de Tradução [on-line]. } \\
\text { Vol. } 38, \mathrm{n}^{\circ} 2.2018 .\end{array}$ \\
\hline S06 & Geometría del fraude & $\begin{array}{l}\text { Cuadernos de Contabilidade } \\
\text { [online]. Vol.18, } \mathrm{n}^{\circ} .45 .2017 .\end{array}$ \\
\hline S07 & $\begin{array}{l}\text { Habilidades del pensamiento creativo } \\
\text { asociadas a la escritura de textos multimodales. } \\
\text { Instrumento para su evaluación en la } \\
\text { Educación Básica Primari }\end{array}$ & $\begin{array}{l}\text { Folios: Revista de la Facultad de } \\
\text { Humanidades. } 2017 .\end{array}$ \\
\hline S08 & $\begin{array}{l}\text { O monitoramento metacognitivo em tarefas } \\
\text { que envolvem a criatividade verbal }\end{array}$ & $\begin{array}{l}\text { Psicologia: Teoria e Pesquisa. } \\
\text { Vol. 32, } n^{\circ} 3.2016\end{array}$ \\
\hline S09 & $\begin{array}{l}\text { Motim: o 'pensamento relacional' do riso } \\
\text { como contágio em uma dramaturgia de } \\
\text { processo }\end{array}$ & $\begin{array}{l}\text { Revista Brasileira de Estudos da } \\
\text { Presença, Vol. 7, } \mathrm{n}^{\circ} \text { 1. } 2017 .\end{array}$ \\
\hline S10 & $\begin{array}{l}\text { El diseño industrial: las fronteras confusas de } \\
\text { la creatividad }\end{array}$ & $\begin{array}{l}\text { Ciencia, Docencia y Tecnología, } \\
\text { Vol. 27, } n^{\circ} .53 .2016 .\end{array}$ \\
\hline S11 & $\begin{array}{l}\text { Educación artística y formación ciudadana: } \\
\text { espacio para forjar la sensibilidad en la } \\
\text { Corporación Colegio San Bonifacio, de Ibagué, } \\
\text { Colombia }\end{array}$ & $\begin{array}{l}\text { Entramado [online].Vol.12, } \mathrm{n}^{\circ} 2 . \\
2016 .\end{array}$ \\
\hline S12 & La estimulación de los di ferentes tipos de & Forma y Función Vol. 29, n. ${ }^{\circ} 1 .$. \\
\hline
\end{tabular}

${ }^{5}$ SciELO (Scientific Electronic Library Online) é uma biblioteca eletrônica, de livre acesso e modelo cooperativo de publicação digital de periódicos científicos. < https://scielo.org/>

Recebido em: $15 / 07 / 2020$

Aceito em: $1 \% 12 / 2020$ 


\begin{tabular}{|c|c|c|}
\hline & $\begin{array}{l}\text { pensamiento creativo em niños entre los } 8 \text { y los } \\
11 \text { años, a través de la escritura de mitos sobre } \\
\text { el origen de } 1 \text { universo }\end{array}$ & 2016 \\
\hline S13 & Taxonomías sobre creatividad & $\begin{array}{l}\text { Revista de Psicología, Vol. } 34 . \\
2016 .\end{array}$ \\
\hline S14 & $\begin{array}{l}\text { Percepción de la creatividad en niños, padres y } \\
\text { pares: efectos en la producción creativa }\end{array}$ & $\begin{array}{l}\text { Pensamiento Psicológico, Vol. 13, } \\
\mathrm{n}^{\circ} 2.2015 .\end{array}$ \\
\hline S15 & $\begin{array}{l}\text { Efeitos de um programa de criatividade para } \\
\text { professoras em alunos do ensino fundamental }\end{array}$ & $\begin{array}{l}\text { Estudos de Psicologia I } \\
\text { Campinas. } 2015\end{array}$ \\
\hline S16 & $\begin{array}{l}\text { La creación de videojuegos en ciencias } \\
\text { naturales y la competencia para resolver } \\
\text { problemas }\end{array}$ & $\begin{array}{l}\text { Revista Lasallista de } \\
\text { Investigación. Vol. 12, no } 2.2015\end{array}$ \\
\hline S17 & $\begin{array}{l}\text { Criatividade no contexto educacional: análise } \\
\text { de publicações periódicas e trabalhos de pós- } \\
\text { graduação na área da psicologia }\end{array}$ & 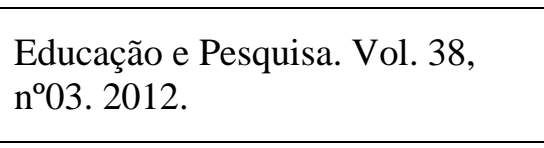 \\
\hline S18 & $\begin{array}{l}\text { Características de superdotação em um par de } \\
\text { gêmeos monozigóticos }\end{array}$ & Psico-USF. Vol. 16, n³. 2011. \\
\hline S19 & $\begin{array}{l}\text { Criatividade e inteligência: analisando } \\
\text { semelhanças e discrepâncias no } \\
\text { desenvolvimento }\end{array}$ & $\begin{array}{l}\text { Estudos de Psicologia, Vol. 15, } \\
\mathrm{n}^{\circ} 3.2010 .\end{array}$ \\
\hline S20 & $\begin{array}{l}\text { O pensamento criativo de Paul Klee: arte e } \\
\text { música na constituição da Teoria da Forma }\end{array}$ & $\begin{array}{l}\text { PER MUSI - Revista Acadêmica } \\
\text { de Música - } \mathrm{n}^{\circ} 21.2010 .\end{array}$ \\
\hline S21 & $\begin{array}{l}\text { Superdotação: conceitos e modelos de } \\
\text { diagnóstico e intervenção psicoeducativa }\end{array}$ & $\begin{array}{l}\text { Revista Brasileira Educação } \\
\text { Especial. Vol.15, } \mathrm{n}^{\circ} 1.2009 .\end{array}$ \\
\hline S22 & $\begin{array}{l}\text { Estudo comparativo sobre superdotação com } \\
\text { famílias em situação socioeconômica } \\
\text { desfavorecida }\end{array}$ & $\begin{array}{l}\text { Revista Brasileira de Educação } \\
\text { Especial. Vol.15, nº } 1.2009 .\end{array}$ \\
\hline $\mathbf{S 2 3}$ & Subjetividade e arte de rua: $100 \%$ Graffit & $\begin{array}{l}\text { Revista Semestral da Associação } \\
\text { Brasileira de Psicologia Escolar e } \\
\text { Educacional (ABRAPEE). Vol. } \\
12 \mathrm{n}^{\circ} \text { 2. 2008. }\end{array}$ \\
\hline S24 & $\begin{array}{l}\text { Criatividade escolar: relação entre tempo de } \\
\text { experiência docente e tipo de escola }\end{array}$ & $\begin{array}{l}\text { Revista Semestral da Associação } \\
\text { Brasileira de Psicologia Escolar e } \\
\text { Educacional (ABRAPEE). Vol. } \\
12, \mathrm{n}^{\circ} 1.2008\end{array}$ \\
\hline S25 & $\begin{array}{l}\text { Relação entre criatividade, inteligência e } \\
\text { autoconceito em alunos monolíngües e } \\
\text { bilíngües }\end{array}$ & $\begin{array}{l}\text { Psicologia Escolar e Educacional. } \\
\text { Vol. } 9, \mathrm{n}^{\mathrm{o}} 1.2005 .\end{array}$ \\
\hline S26 & $\begin{array}{l}\text { Habilidades de pensamento criativo em } \\
\text { crianças institucionalizadas e não } \\
\text { institucionalizadas }\end{array}$ & $\begin{array}{l}\text { Revista Estudos de Psicologia, } \\
\text { PUC. Vol. 20, n ³. } 2003 .\end{array}$ \\
\hline S27 & $\begin{array}{l}\text { A pesquisa histórica no ensino: saberes } \\
\text { necessários à prática docente. }\end{array}$ & $\begin{array}{l}\text { Transinformação, } 15(2): \text { p. } 165- \\
\text { 174. } 2003 \text {. }\end{array}$ \\
\hline S28 & $\begin{array}{l}\text { Fruit Fly (Diptera: Tephritidae) Research in } \\
\text { Latin America: myths, realities and dreams }\end{array}$ & $\begin{array}{l}\text { An. Soc. Entomol. Brasil. Vol. 28, } \\
\text { n4. } 1999 .\end{array}$ \\
\hline S29 & $\begin{array}{l}\text { Desarrollo de competencias de pensamiento } \\
\text { creativo y práctico para iniciar un plan de } \\
\text { negocio: diseño de evidencias de aprendizaje }\end{array}$ & $\begin{array}{l}\text { Revista Iberoamericana para la } \\
\text { Investigación y el Desarrollo } \\
\text { Educativo. Vol.9. } \mathrm{n}^{\circ} 17.2018\end{array}$ \\
\hline S30 & $\begin{array}{l}\text { Desarrollo de una escala de medición de } \\
\text { habilidades metaacadémicas para niños de } 4 .^{\circ} \text {, } \\
5 .^{\circ} \text { y } 6 .^{\circ} \text { de primaria }\end{array}$ & $\begin{array}{l}\text { Revista Iberoamericana para la } \\
\text { Investigación y el Desarrollo } \\
\text { Educativo. Vol.9. n } \text { n } 17.2018\end{array}$ \\
\hline C01 & $\begin{array}{l}\text { Creative thinking and entrepreneurial behavior } \\
\text { among k-12 teachers: a predictive study }\end{array}$ & $\begin{array}{l}\text { Psico (Porto Alegre).Vol } \\
49, \mathrm{n}^{\circ} 4,2018 .\end{array}$ \\
\hline
\end{tabular}

Recebido em: 15/07/2020

Aceito em: $1 \% 12 / 2020$ 


\begin{tabular}{|c|c|c|}
\hline $\mathrm{CO2}$ & Eficácia sem razão [da matemática] & $\begin{array}{l}\text { Caderno Brasileiro de Ensino de } \\
\text { Física. Vol. 33, no } 2.2016 .\end{array}$ \\
\hline $\mathrm{CO3}$ & $\begin{array}{l}\text { Criatividade e desenvolvimento do pensamento } \\
\text { criativo nos estudos de Torrance, Ostrower e } \\
\text { Majmutov }\end{array}$ & $\begin{array}{l}\text { Research, Society and } \\
\text { Development. Vol. 3, n }{ }^{\circ} 1.2016 .\end{array}$ \\
\hline $\mathrm{C04}$ & $\begin{array}{l}\text { Invariancia de medidas de la prueba de figuras } \\
\text { del test de pensamiento creativo de Torrance } \\
\text { según la edad: un estudio en niños y } \\
\text { adolescentes de habla hispana }\end{array}$ & $\begin{array}{l}\text { Cuadernos de Neuropsicología } \\
\text { Panamerican Journal of } \\
\text { Neuropshychology. Vol. } 7 \mathrm{n}^{\circ} 6 \text {. } \\
2013 \text {. }\end{array}$ \\
\hline $\mathrm{C05}$ & Critical thinking in kindergarten & $\begin{array}{l}\text { Telemark University College } \\
\text { Norway childhood \& philosophy. } \\
\text { Vol. } 6, \mathrm{n}^{\circ} 11.2010 .\end{array}$ \\
\hline C06 & $\begin{array}{l}\text { A utilização de ambiente visual de } \\
\text { programação para a contribuição do } \\
\text { desenvolvimento do processo criativo }\end{array}$ & $\begin{array}{l}\text { Revista Intersaberes. Vol.11, } \\
\mathrm{n}^{\circ} 24.2016 .\end{array}$ \\
\hline
\end{tabular}

Fonte: Autoras, 2020

Na quinta etapa da revisão bibliográfica acontece a extração dos dados na qual "após os revisores terem identificado todos os estudos que devem ser incluídos na revisão, é preciso que eles extraiam sistematicamente as informações aplicáveis de cada estudo" (OKOLI, 2015, p.884, tradução nossa). Com esse intuito, foram elaborados inventários para cada um dos 36 artigos encontrados, quando foram selecionadas algumas informações relevantes, como: autores, ano de publicação, título, instituição dos autores, periódicos, objetivos, métodos de pesquisa, nível de ensino, área do conhecimento, referenciais teóricos sobre "pensamento criativo" e excertos do corpo do artigo que apresentavam a expressão "pensamento criativo".

Em seguida, na etapa 6, denominada "Avaliar a qualidade" ou "Triagem para exclusão", os revisores precisam explicar os critérios utilizados para excluir documentos por qualidade insuficiente. Diante disso, foi realizada a leitura dos 36 inventários com o objetivo de analisar e avaliar a qualidade dos artigos perante os objetivos estabelecidos para essa revisão.

A sétima etapa é conhecida como a sintetização dos estudos, isto é, a análise propriamente dita. Essa etapa envolve a "combinação dos fatos extraídos dos estudos usando técnicas apropriadas, quantitativas, qualitativas ou ambas" (OKOLI, 2015, p.884, tradução nossa). Nessa etapa foram realizadas a análise e a síntese dos inventários por meio dos pressupostos da Análise de Conteúdo (AC), proposto por Bardin (2011). Os encaminhamentos analíticos da AC são distribuídos em três fases 
distintas: 1) a pré-análise; 2) a exploração do material; e 3) o tratamento dos resultados, a inferência e a interpretação.

A pré-análise é definida como a fase de organização e intuição do pesquisado (BARDIN, 2011). Nesta fase foram realizadas as leituras flutuantes dos artigos e a seleção dos mesmos e, além disso, foram idealizados os objetivos, as questões de pesquisa e elaborados os inventários para a análise dos artigos.

Na segunda fase da AC, ou seja, a exploração do material, os artigos foram codificados (S01-S30 e C01-C06), classificados e categorizados. De acordo com Bardin (2011), a categorização é "uma operação de classificação de elementos constitutivos de um conjunto por diferenciação e, em seguida, por reagrupamento segundo o gênero (analogia), com os critérios previamente definidos" (BARDIN, 2011, p. 147). Tais critérios podem ser estabelecidos a priori ou a posteriori. Para essa revisão, as categorias foram definidas a posteriori, por meio de aproximações de significados.

A terceira fase da AC é intitulada tratamento dos resultados, a inferência e a interpretação, fase na qual "os resultados brutos são tratados de maneira a serem significativos e válidos" (BARDIN, 2011, p. 131). É nessa etapa que o analista propõe inferências e apresenta interpretações dos objetivos previstos.

Por fim, na oitava etapa é proposta a escrita da revisão. Nessa fase, "além dos princípios padrão a serem seguidos na escrita dos trabalhos de pesquisa, o processo de uma revisão sistemática da literatura precisa ser relatado com detalhes suficientes, de modo que outros pesquisadores possam reproduzi-lo" (OKOLI, 2015, p. 884, tradução nossa).

\section{RESULTADOS E DISCUSSÃO}

Iniciamos esta seção apresentando as características gerais das produções, como: a temporalidade das publicações, os países em que se localizam as instituições dos autores e periódicos, as áreas de conhecimento a que os artigos estavam relacionados e os referenciais teóricos utilizados para fundamentar as ideias de pensamento criativo. Além disso, em um segundo momento apresenta-se a categorização dos artigos, de acordo com os contextos investigativos em que o pensamento criativo vem sendo empregado pelos autores. 
De acordo com os levantamentos realizados, constatou-se que os artigos que discutem o pensamento criativo encontram-se publicados desde 1999, porém, apresentam maior ocorrência a partir do ano de 2015, computando $60 \%$ dos artigos analisados nesta pesquisa.

Constatou-se que os anos de 2016 e 2018 foram os que mais apresentaram publicações sobre a temática, tendo sido desenvolvidos 8 trabalhos (22\%) em 2016, e 7 trabalhos (19\%) em 2018. Tais dados evidenciam que a temática, embora com discussões iniciais na década de 1950, em contextos norte-americanos, tem surgido como mais intensidade em debates atuais (2016 e 2018), no Brasil e na América Latina.

Com relação aos países em que se localizam as instituições dos autores, destaca-se que 19 artigos (53\%) foram de instituições brasileiras, 5 artigos (14\%) de instituições colombianas, 4 artigos (11\%) de instituições mexicanas, 3 artigos (8\%) de instituições argentinas e 2 artigos (5\%) de instituições chilenas. Além disso, observa-se a presença de mais 3 artigos de diferentes instituições: um dos Estados Unidos, um da Bélgica e um de Portugal, representando 3\% cada. Em consonância, é importante ressaltar que 26 publicações (72\%) estão presentes em periódicos brasileiros, 6 publicações (17\%) em periódicos colombianos, 2 publicações $(6 \%)$ em periódicos argentinos e 2 publicações $(6 \%)$ em periódicos mexicanos.

Essas características podem ser resultado das bases de dados escolhidas, uma vez que tais bases selecionam, principalmente, artigos brasileiros e da América Latina.

Destaca-se, também, que os artigos selecionados nesta revisão eram de diversas áreas do conhecimento, conforme apresentado na figura 1. Pode-se afirmar que dentre os artigos analisados, a Educação é a área do conhecimento que mais se destaca, com aproximadamente $31 \%$ das publicações, seguida da Psicologia, com 28\%. Acreditamos que a elevada representatividade de publicações nestas áreas do conhecimento, pode estar correlacionada com a existência de programas e linhas de pesquisa interessados em investigar o pensamento criativo e/ou a criatividade, tanto no desenvolvimento quanto no comportamento humano. Além disso, estas áreas do conhecimento - a Educação e a Psicologia - apresentam nos últimos anos um maior arcabouço de referenciais teóricos que tratam a temática em questão. 
$\mathrm{Na}$ área da Educação, o pensar criativamente é discutido no desenvolvimento de processos de ensino e aprendizagem de professores e alunos e, além disso, a temática se faz presente em diversos documentos nacionais e internacionais. Já a alta representatividade no campo da Psicologia está correlacionada aos inúmeros testes propostos para avaliarem o pensamento criativo e a criatividade.

As demais áreas apresentam-se ainda de forma amena, e em relação aos artigos relacionados à área de Ensino de Ciências (Química, Física e Biologia), estes ainda são pouco representativos.

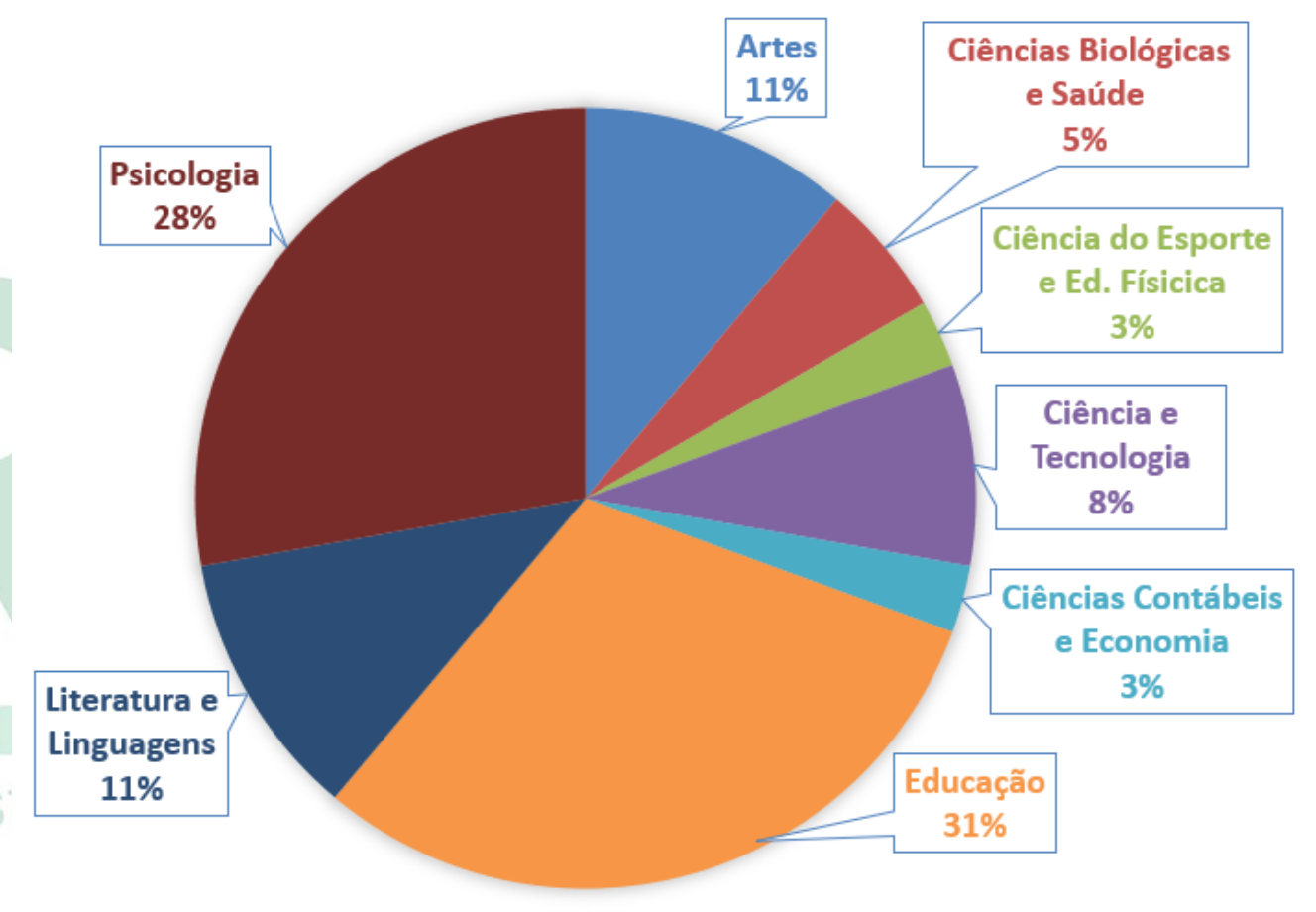

Figura 1 - Áreas de conhecimento dos artigos analisados.

Fonte: Autoras, 2020.

Outro aspecto importante levado em consideração para a análise foi a existência ou não de referenciais teóricos acerca do pensamento criativo e da criatividade. Dessa maneira, foram determinadas duas categorias, presentes no Quadro 2:

Quadro 2 - Presença de referenciais teóricos acerca do pensamento criativo/criatividade.

\begin{tabular}{|c|l|c|c|}
\hline Categoria & \multicolumn{1}{|c|}{ Descrição } & Artigos & Porcentagem \\
\hline & $\begin{array}{l}\text { Publicações que mencionam a } \\
\text { RT1 }\end{array}$ & $\begin{array}{l}\text { S01, S03, S04, S07, S08, } \\
\text { S09, S12, S13, S14, S15, }\end{array}$ & \\
& $\begin{array}{l}\text { 2riatividade e utilizam referenciais } \\
\text { teóricos acerca do tema. }\end{array}$ & $\begin{array}{c}\text { S17, S18, S19, S21, S22, } \\
\text { S24, S25, S26, S29, C01, }\end{array}$ & $64 \%$ \\
& C03, C04 e C05 & \\
\hline RT2 & Publicações que mencionam a & S02, S05, S06, S10, S11, & $36 \%$ \\
\hline
\end{tabular}

Recebido em: $15 / 07 / 2020$

Aceito em: $1 \% 12 / 2020$ 


\begin{tabular}{|l|l|c|c|}
\hline & $\begin{array}{l}\text { expressão Pensamento Criativo e/ou } \\
\text { Criatividade, mas não utilizam } \\
\text { referenciais teóricos acerca do } \\
\text { tema. }\end{array}$ & S16, S20, S23, S27, S28, C02 e C06 & \\
\hline
\end{tabular}

Fonte: Autoras, 2020

Foram identificados 23 artigos (64\%) que utilizam referenciais sobre PC, os quais foram alocados na categoria RT1. Contrapondo-se a isso, 13 dos artigos (36\%) foram alocados em RT2, pois esses mencionam a expressão pensamento criativo e/ou criatividade, no entanto, não utilizam referenciais teóricos que contribuam para a compreensão do assunto abordado. Os principais autores mencionados nessas publicações estão listados no Quadro 3: nos artigos.

Quadro 3 - Principais referenciais teóricos de pensamento criativo e criatividade mencionados

\begin{tabular}{|c|c|}
\hline $\begin{array}{c}\text { Referenciais } \\
\text { Teóricos de } \\
\text { Pensamento } \\
\text { Criativo }\end{array}$ & $\begin{array}{l}\text { Bailin; Siegel (2003), Blázquez (2009), Cachinero (2007), Craft (2001), Dam et } \\
\text { al. (2010), Fleith; Alencar (2005), Gómez (2005), Garaigordobil (2004), } \\
\text { Garaigordobil e Pérez (2002), Glass (2004), Guilford (1950), Hernández et al. } \\
\text { (2015), Lacin; Balkan (2010), Majmutov (1983), Ostrower (2003, 2013), Salles } \\
\text { (2006), Schnarch (2012), Torrance (1966, 1972, 1974, 1977), Urban; Jellen } \\
\text { (1996), Vizcaya (2010), Wang (2012) e Wechsler (2004a, 2004b). }\end{array}$ \\
\hline $\begin{array}{c}\text { Referenciais } \\
\text { teóricos de } \\
\text { Criatividade }\end{array}$ & $\begin{array}{l}\text { Cao; Trigo (1998), Corazza (2016), Cropley, Kaufman \& Cropley (2011), } \\
\text { Csikszentmihalyi (1999, 2006), De Bono (1970, 1976), De Prado (2001), Fleith; } \\
\text { Alencar, (2004, 2005, 2008), Fuentes; Torbay (2004), Grégoire (2016), Jellen } \\
\text { (1996), Kaufmann; Beghetto (2009), Peirce (2011), Sternberg (2006), Torrance } \\
\text { (1979,1990), Torrance; Safter (1999), Taylor (2009), Torre; Urban; Wechsler, } \\
\text { S. M. (2002a, 2002b, 2004, 2009) e Violant (2006). }\end{array}$ \\
\hline
\end{tabular}

Fonte: Autoras, 2020

Um segundo movimento analítico realizado foi identificar e caracterizar os contextos investigativos em que o pensamento criativo foi empregado pelos autores das produções. Após as análises, foram estabelecidas 6 categorias descritas no Quadro 4.

Quadro 4 - Contextos investigativos de pensamento criativo apresentados nos 36 artigos.

\begin{tabular}{|c|c|c|c|}
\hline Categoria & Descrição & Artigos & Quantidade \\
\hline \multirow{2}{*}{ C1 } & $\begin{array}{c}\text { Avaliam o pensamento criativo a partir de } \\
\text { distintos instrumentos }\end{array}$ & $\begin{array}{c}\text { S17, S18, S19, S15, } \\
\text { S22, S24, S25, S26, } \\
\text { S30, C01, C04 }\end{array}$ & 15 \\
\hline C2 & $\begin{array}{c}\text { Utilizam a expressão "pensamento } \\
\text { criativo" sem aprofundá-la. }\end{array}$ & $\begin{array}{c}\text { S05, S06, S10, S20, } \\
\text { S23, S27, S28, C02 }\end{array}$ & 8 \\
\hline \multirow{2}{*}{ C3 } & $\begin{array}{c}\text { Sugerem que determinadas propostas de } \\
\text { ensino podem promover o pensamento } \\
\text { criativo. }\end{array}$ & $\begin{array}{c}\text { S02, S04, S07, S11, } \\
\text { S16, S29 e C06 }\end{array}$ & 7 \\
\hline
\end{tabular}

Recebido em: $15 / 07 / 2020$

Aceito em: $1 \% / 12 / 2020$ 


\begin{tabular}{|c|c|c|c|}
\hline C4 & $\begin{array}{c}\text { Relacionam diferentes perspectivas do } \\
\text { pensamento criativo com outros } \\
\text { referenciais teóricos. }\end{array}$ & S09, S13, C03 e C05 & 4 \\
\hline C5 & $\begin{array}{c}\text { Investiga ideias e compreensões de } \\
\text { professores e alunos acerca do } \\
\text { pensamento criativo. }\end{array}$ & S01 & 1 \\
\hline C6 & $\begin{array}{c}\text { Relata desafios ao pensamento criativo } \\
\text { nas Ciências }\end{array}$ & S03 & 1 \\
\hline
\end{tabular}

Fonte: Autoras, 2020

Nas seções a seguir são apresentados detalhes de cada uma das categorias com excertos de artigos representativos.

\section{(C1): AVAliam O PENSAMENTO CRIATIVO A PARTIR DE DISTINTOS INSTRUMENTOS}

Os trabalhos presentes nessa categoria analisam as contribuições de instrumentos que avaliam o pensamento criativo. Foram encontrados 15 artigos (42\%), sendo a categoria de maior representatividade. Os artigos alocados nesta categoria são predominantemente das áreas de Psicologia e Educação.

Um exemplo é o S08, no qual as autoras investigaram o monitoramento metacognitivo de 82 universitários, de sete cursos diferentes de duas universidades públicas (Psicologia, Música, Engenharia Elétrica, Matemática, Bacharel em Ciência da Informação, Engenharia da Computação, Bacharel em Ciência da Computação), em tarefas envolvendo processos criativos verbais. Para isso, realizaram o Teste de Pensamento Criativo, proposto por Torrance.

Foi Torrance o primeiro investigador a analisar o pensamento criativo em uma perspectiva pedagógica, levando em consideração que o potencial criativo sofre influência do desenvolvimento do indivíduo, do meio social em que ele vive e dos processos de aprendizagem envolvidos em sua trajetória. Dessa forma, Torrance buscou identificar quais circunstâncias permitiam melhorar os resultados criativos (TSCHIMMEL, 2010).

Como resultado as autoras destacam que "os universitários parecem possuir poucas habilidades de monitoramento metacognitivo em tarefas que envolvam a criatividade, visto que as relações entre os desempenhos reais e estimados tenderam a ser fracas" (S08, p. 06).

Recebido em: $15 / 07 / 2020$

Aceito em: $1 \% 12 / 2020$ 
No artigo S26 foram analisadas as diferenças em habilidades de pensamento criativo em crianças de 7 a 12 anos de idade, crianças essas institucionalizadas e não institucionalizadas. Para isso, os sujeitos de pesquisa realizaram o teste de natureza verbal da Bateria Torrance de Pensamento Criativo e o Teste de Pensamento Criativo Produção Divergente. Após a realização e análise dos testes, os autores do artigo apontaram que:

\begin{abstract}
Não foram observadas diferenças significativas nas medidas de pensamento criativo entre crianças institucionalizadas e não institucionalizadas. Diferença significativa entre gêneros foi observada no Teste de Pensamento Criativo Produção Divergente, a favor do gênero masculino, paralelamente a uma interação entre gênero e instituição neste teste. Observou-se também uma relação positiva entre os escores dos dois testes utilizados (S26, p. 23).
\end{abstract}

Todos os artigos classificados nesta categoria avaliam o pensamento criativo a partir de alguns instrumentos. Nessa categoria (C1) observou-se também que 14 dos 15 artigos alocados empregam referenciais teóricos de pensamento criativo e/ou criatividade. Apenas o S30 não faz o uso de referenciais teóricos acerca do tema. Dentre alguns referenciais teóricos presentes nos artigos estão: Torrance, Wechsler, Cachinero, Garaigordobil e Pérez, Fleith e Alencar, entre outros.

\title{
(C2): UTILIZAM A EXPRESSÃO “PENSAMENTO CRIATIVO" SEM APROFUNDÁ-LA
}

Os artigos enquadrados nessa categoria apenas mencionam a expressão "pensamento criativo", sem aprofundá-la, e também não fazem uso de referenciais teóricos específicos. Os 8 artigos (22\%) alocados na C2 são de diferentes áreas do conhecimento como Artes, Literatura e Linguagens, Ciências Biológicas e Saúde, Ciências Contábeis e Economia, Ciência e Tecnologia e Educação.

O artigo S06, de Ciências Contábeis/Economia, aborda o fenômeno da fraude corporativa sob uma perspectiva psicológica e afirma que o pensamento criativo tende a influenciar na inovação. Mesmo sem discussões mais aprofundadas sobre o tema, e sem a presença de referenciais teóricos, a temática se insere na definição de Morais e Fleith (2017), a qual diz que "a criatividade acontece na interação entre aptidões, processos e ambiente, interação pela qual é produzido algo que é definido como novo e útil num dado contexto social" (p. 04). 
Ainda como exemplo dessa categoria enquadra-se o artigo C02 que cita a expressão "pensamento criativo" apenas em suas palavras-chave, sem enfatizá-lo no decorrer do texto. Consideramos o fato desse artigo apresentar o termo pensamento criativo nas palavras-chave e não tratar do tema no corpo do artigo, uma contradição, já que as palavras-chave resumem os temas principais de um texto, além de identificarem ideias e temas importantes para servirem de referência às pesquisas.

O objetivo de C02 é propor uma tradução comentada de um conto de "ficção matemática", além disso, também propõe uma reflexão sobre os rumos do desenvolvimento científico propiciados pela Matemática e pela Física. Os autores de C02 ainda procuram trabalhar a motivação com os estudantes na busca de soluções não triviais para problemas científicos e filosóficos, no entanto, não utilizam mais a expressão pensamento criativo ao longo do texto.

É possível observar que as publicações presentes nesta categoria $(\mathrm{C} 2)$, não possuem como foco central o pensamento criativo, o que permite a interpretação de que a expressão é empregada de maneira casual no transcorrer dos textos.

\section{(C3): SUGEREM QUE DETERMINADAS PROPOSTAS DE ENSINO PODEM PROMOVER O PENSAMENTO CRIATIVO}

Os artigos alocados nessa categoria enfatizam que a promoção do pensamento criativo pode ocorrer por meio do uso de determinados recursos pedagógicos e abordagens de ensino e aprendizagem específicas. Embora seja consenso que o pensamento criativo é uma das competências desejáveis para o cidadão contemporâneo, como mencionado no relatório do Fórum Econômico Mundial, tal competência não é considerada inata e pode ser promovida em diferentes domínios e, entre eles, o contexto educacional (WORLD ECONOMIC FORUM, 2016).

Nessa categoria foram alocados sete artigos (19\%). Os artigos são das seguintes áreas: Artes, Ciências Biológicas e Saúde, Ciências do Esporte e Educação Física, Literatura e Linguagens, Ciência e Tecnologia e Educação. 
No artigo S07 os autores argumentam que o uso das TIC's - Tecnologias de Informação e Comunicação - no Ensino Básico pode promover as habilidades de pensamento criativo e a escrita de textos multimodais ${ }^{6}$. Esse estudo apresenta

[...] caráter exploratório e foi desenvolvido a partir de uma metodologia mista com estudantes de quinto ano de uma instituição educativa rural. O propósito geral é contribuir para o uso pedagógico das TIC no Ensino Básico através da indagação das habilidades do pensamento criativo e a escrita de textos multimodais (S07, p. 03, tradução nossa).

Ainda em S07 os autores afirmam que a correlação entre o pensamento criativo e a escrita de textos multimodais pode ser traduzida em um "argumento pedagógico e didático, esse para a definição de critérios que excedam a dimensão instrumental da utilização das TIC na escola, exigindo processos mais abrangentes, reflexivo e complexo durante o desenvolvimento de propostas didáticas" (S07, p. 12, tradução nossa).

Outro exemplo alocado em C3 é o artigo S16 no qual o autor apresenta uma sequência didática desenvolvida no contraturno de uma escola pública, com alunos da sexta série (10 e 11 anos de idade). Nessa Sequência Didática, a criação de videogames é adotada como estratégia de ensino e aprendizagem, por promover múltiplas competências, dentre as quais se enquadra o pensamento criativo.

Maronn (2019) afirma que "é possível perceber que a realização de uma atividade prática é muito importante, pois tem como intuito proporcionar a capacidade de formulação de hipóteses" estimulando novamente a criatividade dos alunos, pois assim podem ser levantados argumentos para responder estas perguntas, trabalhando com o pensamento criativo desses alunos (MARONN, 2019, p. 308).

Tais propostas de ensino estão relacionadas com a Base Nacional Comum Curricular (BNCC), a qual apresenta trechos envolvendo a expressão "pensamento criativo" relacionados ao fato de que as experiências que as crianças adquirem, em diferentes contextos, estimulam sua curiosidade e capacidade de formulação de perguntas, conforme explicitado a seguir:

O estímulo ao pensamento criativo, lógico e crítico, por meio da construção e do fortalecimento da capacidade de fazer perguntas e de avaliar respostas, de

\footnotetext{
${ }^{6}$ Os autores consideram como textos multimodais aqueles que têm mais de um modo de representação de ideias, nos quais o significado é comunicado através da sincronização, simultaneidade e complementaridade.
}

Recebido em: $15 / 07 / 2020$

Aceito em: $1 \% 12 / 2020$ 
argumentar, de interagir com diversas produções culturais, de fazer uso de tecnologias de informação e comunicação, possibilita aos alunos ampliar sua compreensão de si mesmos, do mundo natural e social, das relações dos seres humanos entre si e com a natureza (BRASIL, 2017, p. 60).

Embora os 7 artigos tenham discutido acerca do "pensamento criativo" e/ou da "criatividade", apenas 3 deles (S04, S07 e S29) apresentaram referenciais teóricos que fundamentam tal perspectiva, dentre eles: Cao e Trigo (1998); Cropley, Kaufman e Cropley (2011); De Bono (1970, 1976); Taylor (2009); Fuentes e Torbay (2004); Torrance (1990); Schnarch (2012); e Hernández et al. (2015).

\section{(C4): RELACIONAM DIFERENTES PERSPECTIVAS DO PENSAMENTO CRIATIVO COM OUTROS REFERENCIAIS TEÓRICOS}

A categoria C4 acomodou 4 artigos, comportando 11\% do corpus deste estudo. Nessa categoria estão as publicações que relacionam diferentes perspectivas do pensamento criativo com outros referenciais teóricos, como por exemplo, referenciais acerca do pensamento crítico e pensamento criativo compreendido como rede. Como exemplo, temos o artigo $\mathrm{C} 03$ que

[...] refere-se a um estudo exploratório de revisão bibliográfica que teve como objetivo identificar diferentes acepções sobre os conceitos de criatividade e pensamento criativo, englobando o pensamento de alguns autores que se destacam nessa área de estudo, nomeadamente Ellis Paul Torrance (1976), Fayga Ostrower (2013) e M. I. Majmutov (1983) (C03, p. 19).

Neste artigo (C03) os autores enfatizam que a criatividade e os processos criativos, "constituem-se em um vasto campo de investigação, envolvendo, não somente aspectos educacionais, mas estéticos, éticos, teóricos, epistemológicos e ontológicos, uma vez que se conduzem aos âmbitos mais diversos da vida humana” (C03, p. 31).

Os mesmos preceitos supracitados também estão presentes nas Diretrizes Curriculares Nacionais para a Educação Básica, esta apresenta como um de seus princípios fundamentais os princípios estéticos que levam em conta "a valorização da sensibilidade, da criatividade, da ludicidade e da diversidade de manifestações artísticas e culturais" (BRASIL, 2013, p. 88).

O artigo C05 também versa a respeito de diferentes compreensões do pensamento criativo, e as confronta com referenciais teóricos de pensamento crítico, como é evidenciado no excerto a seguir:

Recebido em: $15 / 07 / 2020$

Aceito em: $1 \% 12 / 2020$ 
Embora o pensamento crítico possa ser descrito como: "estritamente analítico e avaliativo, um processo algorítmico que consiste em chegar às avaliações corretas das ideias, argumentos ou produtos" (Bailin e Siegel, 2003), o pensamento criativo é descrito como: "Estritamente generativo, é o tipo de pensamento que permite violar as regras" (C05, p. 161, tradução nossa).

Outro exemplo é o artigo S13 no qual os autores realizam uma "compilação dos modelos e taxonomias que oferecem as classificações dos atributos envolvidos na inovação da criatividade" (C04 p. 147, tradução nossa), sendo o pensar criativamente um deles. Em consonância, os autores apontam que

[...] o foco desta compilação de modelos e taxonomias não incide no olhar psicológico conceitual ou experimental do "pensamento criativo", mas levanta uma visão com um sentido prático, de acordo com as propostas de pesquisadores, criadores e usuários em vários campos do conhecimento para sua aplicação em várias profissões ou ambientes acadêmicos (S13, p. 148).

Para isso, os autores mencionam diferentes referenciais teóricos, dentre eles estão: Sternberg (2006), que aborda oito tipos de criatividade; Kaufmann e Beghetto (2009), os quais estabelecem um modelo de criatividade e quatro tipos de produtos e processos, chamados "modelo Four C"; e Cropley e Kaufman (2011), que organizam os tipos de criatividade em cinco tipos de produtos diferentes.

De acordo com Sallles (2006), em S09, o pensamento criativo é definido como uma "rede de conexões, cuja densidade está estreitamente ligada à multiplicidade das relações que a mantém” (SALLES, 2006, p. 17). A autora ainda apresenta algumas particularidades do pensar criativamente em rede, como: a dinamicidade, o inacabamento, a não linearidade, a interação e a transformação.

É importante destacar que os 4 artigos presentes em C4 apresentam referenciais teóricos acerca do pensamento criativo e/ou da criatividade, e ainda os articulam com outros quadros teóricos, como foi destacado nesta seção.

\section{(C5): INVESTIGA IDEIAS E COMPREENSÕES DE PROFESSORES E} ALUNOS ACERCA DO PENSAMENTO CRIATIVO.

Apenas um artigo (3\%) foi alocado nesta categoria. Nessa produção (S01) foram investigadas as opiniões de docentes e discentes a respeito do pensamento criativo no contexto da pós-graduação, em três áreas distintas: Ciências Biológicas, Ciências Exatas e Ciências Humanas. O objetivo do estudo foi 
[...] examinar o papel da criatividade no contexto da pós-graduação, sob a ótica de estudantes e professores. Foram conduzidas entrevistas semiestruturadas com seis discentes e seis docentes de pós-graduação de uma universidade particular e outra pública. Os tópicos abordados incluíam relevância, concepção e características da criatividade, bem como práticas favoráveis e inibidoras (S01, p.01-02).

Ainda de acordo com o autor, tanto alunos como professores consideraram a criatividade importe para o desenvolvimento da pós-graduação, no entanto, "ambos destacaram barreiras de ordem pessoal e institucional à promoção do pensamento criativo" (S01, p.02). Além disso, os professores e estudantes apontam alguns fatores promovedores da criatividade, dentre eles: o trabalho em equipe, as diferentes estratégias de ensino e a interdisciplinaridade. E relatam como barreira no pensar criativamente, a burocracia no ambiente escolar e as aulas repetitivas, por exemplo. É relevante dizer que S01 é a publicação mais recente do corpus dessa revisão bibliográfica, publicada no ano de 2019.

Em relação aos referenciais teóricos, o autor de S01 apresenta descritores que discutem acerca da criatividade, dentre eles estão: Corazza (2016), que descreve sobre a definição dinâmica da criatividade; Cropley (2005) que aborda a criatividade na educação e na aprendizagem; e Csikszentmihalyi (2006) que versa acerca do desenvolvimento da criatividade.

\section{(C6): RELATA DESAFIOS AO PENSAMENTO CRIATIVO NAS CIÊNCIAS}

Na categoria C6 foi alocado um único artigo S03. Neste estudo o autor investiga os fatores que dificultam a criatividade científica e como é possível resolvê-los. Segundo o autor, este é um tema importante na ciência, pois uma pesquisa científica “não deve se restringir ao desenvolvimento e aplicação lógica de ideias já conhecidas, mas deve promover novas ideias para expandir o conhecimento além das fronteiras existentes" (S03, p.229, tradução nossa). Dessa forma, além de estimular o pensamento criativo, deve-se levar em conta os fatores que o dificultam.

Concomitantemente estão relatados diversos obstáculos existentes no pensar criativamente do pesquisador, como é notável no excerto a seguir:

Os obstáculos mais importantes dentro da mente do pesquisador são os obstáculos epistemológicos e o viés cognitivo (viés de confirmação). Enquanto o obstáculo externo mais importante é composto pelas normas sociais, ou seja, a pressão por parte da comunidade científica e, por vezes, por parte de toda a sociedade, para se adequar ao modelo científico dominante (S03, p.229, tradução nossa).

Recebido em: $15 / 07 / 2020$

Aceito em: $1 \% 12 / 2020$ 
Em consonância com o trecho exposto, o autor ainda enfatiza que para superar esses desafios em relação ao pensamento criativo, é necessário que o pesquisador aprenda a questionar seus conhecimentos iniciais e experiências, arriscar-se em apresentar suas ideias e opiniões e, além disso, valorizar a Educação Científica.

Nessa publicação foram utilizados referenciais teóricos acerca da criatividade, como, por exemplo, Grégoire (2016) que retrata a criatividade na Ciência, Peirce (2011) o qual aborda o raciocínio científico criativo, e Vartanian e colaboradores (2003) que discutem acerca da criatividade e do raciocínio indutivo.

\section{CONSIDERAÇÕS FINAIS}

Diante das análises realizadas e considerando as questões que balizaram este estudo: Quais as características das produções a respeito do "Pensamento Criativo"? Em quais contextos investigativos o pensamento criativo foi empregado pelos autores das produções?, destacamos alguns resultados.

Quanto às características gerais dos artigos foram encontradas 36 publicações acerca do tema, sendo a primeira publicada em 1999, com aumento de sua notoriedade a partir de 2015. Constatou-se, também, que essa temática tem sido abordada em diversas áreas do conhecimento, com predomínio nas áreas de Educação (31\%) e Psicologia (28\%), com poucos trabalhos na área de Ensino de Ciências.

Outro resultado é que $64 \%$ dos artigos mencionam referenciais teóricos de pensamento criativo e/ou de criatividade, e $36 \%$ deles não fazem menção a qualquer referencial teórico relacionado à temática, o que acaba corroborando a ideia ingênua de que a expressão - pensamento criativo - serve "para todo o uso", o que pode esvaziar o seu significado.

A análise e interpretação dos 36 artigos também permitiram identificar e caracterizar os contextos investigativos nos quais o pensamento criativo foi empregado pelos autores das produções. Nesta etapa analítica foram identificadas 6 categorias que estão relacionadas aos seguintes enfoques: artigos que avaliam o pensamento criativo a partir de distintos instrumentos (C1); artigos que utilizam a expressão "pensamento criativo", sem aprofundá-la (C2); artigos que sugerem que determinadas propostas de ensino podem promover o pensamento criativo (C3); artigos que relacionam diferentes perspectivas do pensamento criativo com outros referenciais teóricos (C4); artigos que 
investigam ideias e compreensões de professores e alunos acerca do pensamento criativo (C5), e artigos que relatam desafios ao pensamento criativo nas Ciências (C6).

Salienta-se que a categoria de maior representatividade, com $42 \%$ dos artigos é a $\mathrm{C} 1$, na qual se enquadram publicações que avaliam o pensamento criativo a partir de diversos instrumentos como o Teste de Pensamento Criativo proposto por Torrance, o teste de natureza verbal da Bateria Torrance de Pensamento Criativo, e o Teste de Pensamento Criativo - Produção Divergente.

Conseguinte com $22 \%$ de artigos, temos a categoria $\mathrm{C} 2 \mathrm{em}$ que foram alocados os artigos que fazem uso da expressão "pensamento criativo" em situações distintas, no entanto, não apresentam referenciais teóricos e discussões intensas a respeito do tema. Tal atitude revela o uso desta expressão ainda de forma casual, sem compreensões mais aprofundadas.

Nas publicações que foram alocadas em C3, 19\% dos artigos enfatizam diversas propostas de ensino capazes de promoverem o pensamento criativo, como por exemplo: as TIC's; desenvolvimento de atividades artísticas como música e teatro; aplicação de uma sequência didática para criação de um videogame; elaboração de portfólios coletivos na área da saúde; orientações para práticas corporais com crianças; oficinas com utilização de um software (Scratch) e aprendizagem baseada em problemas; e o emprego da metodologia design thinking para os planos dos negócios.

A C4 acomodou 4 artigos, 11\% das publicações, que fazem uso da temática "pensamento criativo" vinculada a outros referenciais teóricos, como por exemplo, referenciais acerca do pensamento crítico e pensamento criativo compreendido como rede.

Em seguida, a categoria $\mathrm{C} 5$ apresenta um único artigo (3\% do corpus) onde foram investigadas as ideias de docentes e discentes a respeito do pensamento criativo no contexto da pós-graduação. E, por fim, em C6, enquadrou-se novamente um único artigo (3\%) que relata os desafios do pensamento criativo nas Ciências, e como o pesquisador/cientista pode superá-los.

Diante do exposto, por meio desse estudo conseguiu-se obter um panorama acerca de estudos que investigam o pensamento criativo, principalmente no que diz respeito às características gerais dessas produções e dos contextos investigativos analisados pelos 
autores. Sob outra perspectiva, vimos que ainda há muito a ser explorado acerca do pensar criativamente em distintas áreas do conhecimento, principalmente no campo da Educação Científica.

\section{REFERÊNCIAS}

ALENCAR, E. M. L. S.; BRUNO-FARIA, M. F.; FLEITH, D. S. A medida da criatividade: possibilidades e desafios. In: ALENCAR, E. M. L. S., BRUNO-FARIA, M. F., e FLEITH, D. S. Medidas de criatividade: teoria e prática. Porto Alegre: Artmed, 2010. p. 11-34.

BARDIN, L. Análise de conteúdo. São Paulo: Edições 70, 2011, 229 p.

BRASIL. Diretrizes Curriculares Nacionais Gerais da Educação Básica. Brasília: MEC, 2013. Disponível em: <http://portal.mec.gov.br/docman/julho-2013-pdf/13677diretrizes-educacao-basica-2013-pdf/file> Acesso em: 26 de maio de 2020.

BRASIL. Base Nacional Comum Curricular. Brasília: MEC, 2017. Disponível em: < http://basenacionalcomum.mec.gov.br/images/BNCC_20dez_site.pdf >. Acesso em: 26 de maio de 2020.

CHAVERRA-FERNÁNDEZ, D. I.; GIL-RESTREPO, C. D. C. Habilidades del pensamiento creativo asociadas a la escritura de textos multimodales. Instrumento para su evaluación en la educación básica primaria. Folios, Colômbia, v. 45, p. 3-15, 2017.

GALLON, M. SILVA; DA SILVA, J. Z.; DO NASCIMENTO, S. S.; DA ROCHA FILHO, J. B. Feiras de Ciências: uma possibilidade à divulgação e comunicação científica no contexto da educação básica. Revista Insignare Scientia-RIS, Cerro Largo, v. 2, n. 4, p. 180-197, Set./Dez. 2019.

ENNIS, R. H. A logical basis for measuring critical thinking skills. Educational Leadership, Alexandria, VA (USA), Association for Supervision and Curriculum Development, v. 43, n. 2, p. 44-48, 1985.

FINK, A. Conducting research literature reviews: from the internet to paper (2nd ed.). Thousand Oaks, CA: Sage. 2005

GUILFORD, J. Creativity. American psychologist, v. 5, p. 444-454, 1950.

MARONN, T. G. Construção de uma horta vertical: Uma abordagem na Educação Infantil para sensibilizar os estudantes sobre os cuidados com o meio ambiente. Revista Insignare Scientia-RIS, Cerro Largo, v. 2, n. 3, p. 303-313, Ago./Out. 2019.

MORAIS, M. F.; FLEITH, S. D. Capítulo 1: Conceito e avaliação da criatividade. Portugal: Centro de Estudos e Recursos em Psicologia, 2017. E-book. Disponível em: $<$ https://www.researchgate.net/publication/320355022_Conceito_e_avaliacao_da_criati vidade>. Acesso em: 26 de maio de 2020.

OKOLI, C. "A Guide to Conducting a Standalone Systematic Literature Review". Communications of the Association for Information Systems, v. 37, Article 43, 2015.

OSTROWER, F. Criatividade e processos criativos. Rio de Janeiro: Vozes, 2013.

Recebido em: $15 / 07 / 2020$

Aceito em: $1 \% 12 / 2020$ 
PICHÓN-RIVIÈRE, E. O processo de criação. São Paulo: Martins Fontes, 1999.

PINO, A. A Produção Imaginária e a Formação do Sentido Estético: reflexões úteis para uma educação humana. Pró-Posições, Campinas, v. 17, n. 2, p. 47-69, maio/ago. 2006.

SALLES, C. A. Redes da Criação: construção da obra de arte. 2. ed. São Paulo: Horizonte, 2006.

SILVA, W. B. Criatividade no ensino de ciências: direcionamento teórico e empírico para o desenvolvimento da criatividade em sala de aula. 2017. Dissertação (Mestrado em Ensino de Ciências) - Programa de pós-graduação em Ensino de Ciências - PPEC, Universidade Estadual de Roraima, Boa Vista, 2017.

TENREIRO-VIEIRA, C. O pensamento crítico na educação científica. Lisboa: Instituto Piaget, 2000.

TORRANCE, E. P. Criatividade: medidas, testes e avaliações. São Paulo: IBRASA, 1976.

TSCHIMMEL, K. C. Sapiens e demens no pensamento criativo do design. 2010. Tese (Doutorado em Design) - Departamento de Comunicação e Arte, Universidade de Aveiro, Aveiro, 2010.

VINCENT-LANCRIN, S.; GONZÁLEZ-SANCHO, C.; BOUCKAERT, M.; DE LUCA, F.; FERNÁNDEZ-BARRERA, M.; JACOTIN, G.; URGEL, J. e VIDAL, Q. Desenvolvimento da criatividade e do pensamento crítico dos estudantes: o que significa na escola. Coordenação geral Instituto Ayrton Senna; Tradução Carbajal Traduções. São Paulo: Fundação Santillana, 2020.

WORLD ECONOMIC FORUM. The future of jobs: employment, skills and workforce strategy for the fourth industrial revolution. Global Challenge Insight Report, World Economic Forum, Geneva. 2016. 